\title{
Letter
}

This article was published in the following Dove Press journal:

International Journal of COPD

27 January 2012

Number of times this article has been viewed

\section{Martino Laurenzi}

Senior Medical Director, Internal Medicine Medical Affairs, Forest Research Institute, Jersey City, NJ, USA
Correspondence: Martino Laurenzi Senior Medical Director, Internal Medicine Medical Affairs Forest Research Institute Harborside Financial Center, Plaza V Jersey City, NJ 073II

$\mathrm{Tel}+\mathrm{I} 2013862106$

$\mathrm{Fax}+\mid \mathrm{I} 2014278200$

Email martino.laurenzi@frx.com
The article "Optimizing management of chronic obstructive pulmonary disease in the upcoming decade" by Russell et $\mathrm{al}^{1}$ (January edition of the International Journal of Chronic Obstructive Pulmonary Disease) provides an overview of the pathophysiology of chronic obstructive pulmonary disease (COPD) and discusses emerging treatment options for managing this disease. I wish to draw your attention to the general information and clinical trial data presented on roflumilast. Several inaccuracies have been noticed in this section as well as in Table 2 of the article.

The most important of these is the authors' statement that roflumilast's therapeutic effects include bronchodilation. Although statistically significant improvements in lung function were observed in clinical trials of roflumilast, these improvements were not determined to be clinically significant. The US prescribing information for roflumilast (DALIRESP ${ }^{\mathrm{TM}}$ [Forest Pharmaceuticals, Inc, St Louis, MO]) specifies in its indication that DALIRESP is not a bronchodilator and is not indicated for the relief of acute bronchospasm. ${ }^{2}$ The Food and Drug Administration-approved indication for DALIRESP is to reduce the risk of COPD exacerbations in patients with severe COPD associated with chronic bronchitis and a history of exacerbations.

In addition, Table 1 lists "Current pharmacologic options for the management of COPD," citing the Global Initiative for Chronic Obstructive Lung Disease (GOLD) guidelines, but the class of phosphodiesterase-4 (PDE-4) inhibitors is not listed. Considering that this article was published in 2011 and that PDE-4 inhibitors were included in the 2010 revision to the GOLD guidelines, ${ }^{3}$ PDE-4 inhibitors should be included in Table 1.

For your reference, I have included a table of additional minor inaccuracies at the end of this letter.

It is understood that authors and editors make every effort to provide scientifically rigorous and concise reporting, and that errors or inaccuracies in such reporting can occur. It is important to identify and correct these so that medical professionals can make informed decisions when prescribing medications. I respectfully ask you to consider publishing a correction to the information about roflumilast, especially to clarify the critical point that it is not indicated for use as a bronchodilator.

\section{References}

1. Russell R, Anzueto A, Weisman I. Optimizing management of chronic obstructive pulmonary disease in the upcoming decade. Int J Chron Obstruct Pulmon Dis. 2011;6:47-61.

2. DALIRESP [package insert]. St Louis, MO: Forest Pharmaceuticals, Inc; 2011. 
3. Global Initiative for Chronic Obstructive Lung Disease (GOLD). Global strategy for the diagnosis, management, and prevention of chronic obstructive pulmonary disease (updated 2010). Available at: http://www.goldcopd.org/Guidelines/guidelines-global-strategy-fordiagnosis-management.html. Accessed December 16, 2011.

4. Calverley PM, Rabe KF, Goehring UM, Kristiansen S, Fabbri LM, Martinez FJ. M2-124 and M2-125 study groups. Roflumilast in symptomatic chronic obstructive pulmonary disease: two randomised clinical trials. Lancet. 2009;374:685-694.
5. Rabe KF, Bateman ED, O'Donnell D, et al. Roflumilast - an oral antiinflammatory treatment for chronic obstructive pulmonary disease: a randomised controlled trial. Lancet. 2005;366:563-571.

6. Fabbri LM, Calverley PM, Izquierdo-Alonso JL, et al. M2-127 and M2-128 study groups. Roflumilast in moderate-to-severe chronic obstructive pulmonary disease treated with longacting bronchodilators: two randomised clinical trials. Lancet. 2009;374:695-703.

Corrections and comments on reporting of roflumilast clinical data in Russell et al'

\begin{tabular}{ll}
\hline Location & As stated \\
\hline Page 52, column 2 & Clinical studies with roflumilast monotherapy \\
& demonstrated improved lung function, \\
& reduced moderate-to-severe exacerbations, \\
& reduced requirement for anti-inflammatory/ \\
& anti-infective medications, \\
& and improved QoL measures ${ }^{4,5}$
\end{tabular}

Page 52, column 2

Page 52, column 2

Page 52, column 2

Page 52, column 2

Table 2, column I, line 35

Table 2, column I, lines 38-40

Table 2, column I, line 55
Similarly, improvements in lung function and exacerbation outcomes were reported when roflumilast was added to tiotropium, or to salmeterol plus fluticasone ${ }^{6}$

Notable side effects with roflumilast include headache, weight loss $(2.5 \mathrm{~kg}$ in all studies at six months and one year), diarrhea, nausea, and stomach ache (ie, gastrointestinal side effects that resulted in a significant early study withdrawal rate) $)^{4-6}$

Notable side effects with roflumilast include headache, weight loss $(2.5 \mathrm{~kg}$ in all studies at six months and one year), diarrhea, nausea, and stomach ache (ie, gastrointestinal side effects that resulted in a significant early study withdrawal rate) ${ }^{4-6}$

Notable side effects with roflumilast include headache, weight loss $(2.5 \mathrm{~kg}$ in all studies at six months and one year), diarrhea, nausea, and stomach ache (ie, gastrointestinal side effects that resulted in a significant early study withdrawal rate) ${ }^{4-6}$

Study: M2-I24 and MI-I25

Assessed roflumilast $500 \mu \mathrm{g}$ once daily versus placebo in symptomatic moderateto-severe COPD

Total $\mathrm{n}=933$

\section{Corrections/comments}

Calverley et al ${ }^{4}$ showed a significant reduction in the rate of exacerbations requiring treatment with systemic corticosteroids, antibiotics, or both $(P=0.0003)$; however, neither study directly measured whether the requirement for anti-inflammatory/anti-infective medications was reduced or otherwise affected by roflumilast treatment

Fabbri et al ${ }^{6}$ described two studies: one in which roflumilast was added to tiotropium alone and one in which roflumilast was added to salmeterol alone. No study added roflumilast to salmeterol plus fluticasone

The source of the $2.5 \mathrm{~kg}$ value is unclear. Calverley et $\mathrm{al}^{4}$ reported between-treatment weight loss as $-2.17 \mathrm{~kg}$; Rabe et al ${ }^{5}$ reported between-treatment weight loss as $-2.2 \mathrm{~kg}$; Fabbri et al ${ }^{6}$ reported between-treatment weight loss as $-2.1 \mathrm{~kg}$ Stomach ache is not reported as a side effect in any of the clinical papers cited

Only one study reported that gastrointestinal side effects resulted in early study withdrawal ${ }^{4}$

Study number should be listed as M2-125, not MI-I 25

Patient population in Calverley et al ${ }^{4}$ is severe-to-very severe, not moderate-to-severe

The total $\mathrm{n}$ should be $743^{4}$

International Journal of COPD

\section{Publish your work in this journal}

The International Journal of COPD is an international, peer-reviewed journal of therapeutics and pharmacology focusing on concise rapid reporting of clinical studies and reviews in COPD. Special focus is given to the pathophysiological processes underlying the disease, intervention programs, patient focused education, and self management protocols.

\section{Dovepress}

This journal is indexed on PubMed Central, MedLine and CAS. The manuscript management system is completely online and includes a very quick and fair peer-review system, which is all easy to use. Visit http://www.dovepress.com/testimonials.php to read real quotes from published authors. 